\title{
Public health response to an incident of secondary chemical contamination at a beach in the United Kingdom
}

\author{
F J L Goodfellow, V S G Murray, S K Ouki, A Iversen, A Sparks, T Bartlett
}

\begin{abstract}
Objectives-To gather enough data from a large scale investigation involving two health authorities, to assess the possible concentrations and routes of exposure and the consequent health implications. To use the data to decide whether a polluted beach should remain open to the public. In Spring 1997, a chemical incident came to light at a beach on the south coast of England when a local resident reported a sulphurous smell, visible signs of oil, and reduced numbers of fishing bait. The beach was situated adjacent to a former gasworks site and was accessible to the public. The incident was reported to the local authority and was initially investigated by the Environment Agency and the local authority. An Environment Agency report confirmed contamination of the beach with cyanide, ammonia, and polycyclic aromatic hydrocarbons (PAHs) with associated potential health risks. The incident was then referred to the local health authorities for investigation.

Methods-The investigation was carried out in four stages: comprehensive sampling and analysis to identify the extent of contamination, followed by an assessment of risk to health; establishment of a long term monitoring programme to identify any changes in contaminant concentrations; investigation of the effects of the contamination on shellfish; and review of the routine monitoring data and current sampling strategy.
\end{abstract}

Results-The initial investigation confirmed that the beach was contaminated, with the most likely source being the adjacent former gasworks site. The level of contamination was not found to be likely to pose a hazard to users of the beach. However, subsequent investigation of shellfish in the area led to warning signs being erected on the beach to prevent human consumption of mussels contaminated with PAHs.

Conclusions-Several lessons can be learnt from this investigation, which can be applied to incident management more generally: the importance of collaboration and coordination; the need for early involvement of the health authority; and the importance of carrying out appropriate sampling and analysis as soon as possible, to assess the risk to health and the environment.

(Occup Environ Med 2001;58:232-238)
Keywords: public health; water pollutants, chemical; hydrocarbons; cyanides

In recent years public health doctors have taken on a much greater role in the investigation of environmental hazards that impact on the health of the general population, including the management of both acute and chronic chemical incidents. The current system, which requires public health doctors within health authorities to manage chemical incidents, has only been in place since $1993 .{ }^{1}$ The recently published NHS guidance "planning for major incidents", states that the health authority "must ensure that satisfactory arrangements are in place for handling the public health and health care aspect of the response to chemical incidents". ${ }^{2}$ The specific role of the health authority is to protect public health; however, to achieve this, the public health doctor needs to be able to identify the routes and levels of exposure and to assess the possible management options of preventing or mitigating exposure.

This paper reports on the investigation into a particular chronic environmental hazard in which there was significant involvement by the health authorities responsible for the affected area. This incident involved the migration of contaminants from an industrial site, previously used as a gasworks, and the consequent contamination of an adjacent beach and seawater. The site in question was on the English south coast. However, it is estimated that there are in the region of 1000 former gasworks sites across the United Kingdom, with most requiring some type of remediation. ${ }^{3}$ Several potentially highly hazardous materials are likely to be present on such sites-for example, sulphides, cyanides, tarry liquids, ammoniacal liquors, coal tar, phenols, and heavy metals. ${ }^{4}$

A potential threat to the health of the public was first identified in April 1997, when contamination of a beach, which was accessible to the public, was reported. Initially, high concentrations of cyanide and polycyclic aromatic hydrocarbons (PAHs) in beach sediment and water runoff from the beach (seepage water) were reported. A series of environmental investigations were subsequently conducted involving several organisations. The focus of this paper is on the role of the health authority in the incident and the actions taken to identify and manage the public health risk caused by the contamination.

The incident occurred at a beach on the south coast of England. The beach was bordered by a road, and the land immediately 
Table 1 Chronology of the incident

\begin{tabular}{|c|c|c|}
\hline Date & $\begin{array}{l}\text { Weeks from } \\
\text { initial report } \\
(n)\end{array}$ & Incident stage \\
\hline 25 April 1997 & 0 & $\begin{array}{l}\text { Local fisherman reported changes in bait to the local authority. } \\
\text { Local authority carried out initial investigation including preliminary } \\
\text { sampling. }\end{array}$ \\
\hline 7 August 1997 & 15 & $\begin{array}{l}\text { Meeting between the two local authorities, the Port Authority and } \\
\text { Environment Agency. } \\
\text { Followed by an environmental investigation by Environment Agency. }\end{array}$ \\
\hline 22 August 1997 & 17 & Second sampling visit by Environment Agency. \\
\hline 20 February 1998 & 43 & $\begin{array}{l}\text { Environment Agency report became available. } \\
\text { Health authorities immediately alerted by the local authority. } \\
\text { Health authority contacted CIRS. }\end{array}$ \\
\hline 24 February 1998 & 43.5 & $\begin{array}{l}\text { Site visit and meeting with the health authorities, CIRS, and all involved } \\
\text { parties. }\end{array}$ \\
\hline 27 February 1998 & 44 & Third sampling visit by Environment Agency and local authorities. \\
\hline 6 March 1998 & 45 & $\begin{array}{l}\text { Meeting between Environment Agency, two local authorities, two health } \\
\text { authorities, and port authority to decide on the further management of } \\
\text { the beach and future long term monitoring programme. }\end{array}$ \\
\hline 19 March 1999 & 99 & Began shellfish sampling and analysis programme. \\
\hline 21 October and 4 November 1999 & 130 and 132 & Meetings to discuss action on mussel contamination. \\
\hline 2 November 2000 & 185 & $\begin{array}{l}\text { Meeting to assess monitoring results to date and review future } \\
\text { monitoring strategy. }\end{array}$ \\
\hline
\end{tabular}

behind was the site of a former gasworks. The entire beach, down to low tide level, belonged to the local port authority. The beach was used as a naturist beach, for line fishing, and there was also offshore commercial fishing, which included fishing for crab and lobster. This beach was not often used by children. The direction of longshore drift was expected to move any contamination from the beach in the direction of a major seaside resort, about 5 miles along the coast. There was no drinking water abstraction in the area.

The problem first came to the attention of the local authority on 25 April 1997, when a local resident reported that there were reduced numbers of bait for fishing on a beach in the local authority area. The fisherman also noticed a sulphurous smell and visible signs of oil whilst digging for bait. The information was passed on to the Environment Agency, who carried out initial sampling of sediment and seawater at the beach. Visual observation of the area showed the existence of patches of oily film on the sea, a phenolic smell in the area, and there was also a possible sighting of pieces of "prussian blue" (ferric ferrocyanide). A local authority investigation was also initiated, including preliminary sampling.

On the 7 August 1997, a meeting was held between the port authority, two local authorities, and the Environment Agency, following which, on 22 August 1997, the Environment Agency took sediment, seawater, and seepage water samples, and conducted a biological survey. A report was produced by the Environment Agency in January 1998, which concluded that the beach was affected by pollution, and the most likely source was the former gasworks. ${ }^{5}$ It also stated that the pollution posed risks to human health, had impacted on the macroinvertebrate fauna within the beach, and was causing ongoing pollution of controlled waters. A very high concentration of PAHs (75 $550 \mathrm{mg} / \mathrm{kg}$ ) was reported in one sediment sample, and also a high concentration of cyanide $(1 \mathrm{~g} / \mathrm{l})$ in seepage water. When the Environment Agency report became available the local authority immediately alerted the health authority of the potential risk to public health and the two health authorities covering the area of concern became involved in the investigation.

\section{Methods}

The chronology of the incident is indicated in table 1. The health investigation began in February 1998 and evolved through four stages from the initial assessment of the extent of the problem to the current stage of continued environmental monitoring and review.

STAGE ONE

Once the health aspect of the incident had been identified, there was a degree of urgency to assess the actual risk to health, to decide whether the hazard was great enough to warrant closure of the beach. The public health implications of beach closure would be considerable. Anxiety would be generated in beach users, and local media coverage would probably be extensive. The first stage was to conduct a detailed environmental investigation to assess the extent and source of the actual contamination and the associated health risk to the public. The health authorities involved contacted the Chemical Incident Response Service (CIRS), which is one of five regional service provider units for chemical incidents across the United Kingdom, and has service level agreements with health authorities to provide toxicological, epidemiological, scientific, and environmental advice about the management of chemical incidents and protection of public health.

A site visit was conducted by CIRS at the end of February 1998 and was attended by representatives of the two health authorities and two local authorities, the Environment Agency, and the local port authority. Assessment of the risks to health from the contamination required confirmation of previous sample results and measurement of the current level of contamination. Therefore, the first action was to instigate a more comprehensive sampling and analysis programme with robust quality control and assurance procedures. The analysis was carried out at two independent laboratories. The second priority was to identify the 
source of the contamination. The Environment Agency collected and analysed samples of the seepage water, seawater, and beach sediment. The local authority also took samples of the same media, which were analysed by the Water Research Centre. Typical chemicals found on gasworks sites were identified and samples were analysed for several of these chemicalsnamely, cyanide, ammonia, PAHs, phenol, and a range of metals. ${ }^{4}$

The aim of this investigation was to gather enough data to assess the possible level and routes of exposure and the consequent health implications to decide whether the beach should remain open to the public. Assessment of the possible health implications from the contamination was conducted by comparing results from sediment samples with the United Kingdom Interdepartmental Committee on the Remediation of Contaminated Land (ICRCL) and Dutch contaminated land standards. ${ }^{6}$ Both sets of standards have been set for soils as opposed to sandy sediment. Seawater and seepage water sample results were compared with United Kingdom drinking water standards and World Health Organisation (WHO) drinking water guidelines. ${ }^{78}$ In this case, consumption of water would have been accidental and low in volume because of its saltiness and also because the low seepage flow rates would have made it difficult to collect large volumes of water. Therefore, the use of these standards and guidelines represented a conservative approach as they are designed for application in the consumption of drinking water and refer to lifetime exposures. At this stage, information was also compiled on the toxicological effects of the substances of concern, summary details can be found in box 1 .

\section{STAGE TWO}

As a follow up to the extensive environmental monitoring investigation carried out in February to March 1998 it was decided that a long term routine monitoring programme should be established by both the Environment Agency and the local authorities. The aim was to be able to assess any changes in the concentrations of contaminants over time and to allow the early identification of any increases to a concentration that may constitute a health risk. Previous monitoring results were used to decide which chemicals should be assessed, the chemicals were restricted to those considered to be of most concern for the impact on human health: cyanide; ammonia; PAHs; phenol; and arsenic. Frequency of monitoring was increased in the summer bathing period.

STAGE THREE

The investigations carried out in stage one also highlighted the possibility that contamination may have spread into the food chain as a result of low level contamination of the seawater. Stage three involved establishing a sampling and analysis programme in the vicinity of the beach to assess the impact of raised PAHs on shellfish in particular. In March 1999, the local authority and Centre for Environment, Fisher-

\section{Ammonia $^{9}$}

Ammonia acts as an alkali. Anhydrous ammonia reacts with moisture in mucosal surfaces (eyes, skin, and respiratory tract) to produce ammonium hydroxide which may cause caustic injury. Ammonia is a severe respiratory tract irritant with acute inhalation effects including a dry mouth with sore throat and eyes, tight chest, headache, ataxia, and confusion. After massive exposures, chronic airway hyperreactivity and asthma, associated with obstructive changes in pulmonary function, may occur. ${ }^{10}$

\section{Hydrogen cyanide ${ }^{9}$}

Cyanide is absorbed by inhalation, ingestion, and through the eyes and intact skin. Cyanides act extremely quickly once absorbed. Principal signs and symptoms of acute systemic effects are headache, dizziness, vomiting, anxiety, confusion, weakness, ataxia, hyperventilation, dyspnoea, hypotension, bradycardia, and collapse. Cyanide may also cause acute effects in the eyes-for example, irritant effects, conjunctivitis, and eyelid oedema-have been reported after exposure to cyanogen chloride. ${ }^{11}$ Effects of chronic exposure to cyanide include respiratory tract irritation, chest discomfort, and exertional dyspnoea, and varying degrees of rhinitis, nasal obstruction, and bleeding have been seen in workers chronically exposed to cyanide. ${ }^{10}$

\section{Polycyclic aromatic hydrocarbons (PAHs) $^{12}$}

In general, PAHs have a low order of acute toxicity in humans. Cancer is the most significant end point of $\mathrm{PAH}$ toxicity. Increased incidents of cancers of the skin, bladder, lung, and gastrointestinal tract have been described in workers exposed to PAHs. Chronic exposure can also produce various non-cancer effects. These chronic effects include eye irritation and photosensitivity, respiratory irritation with cough and bronchitis, leukoplakia, "coal tar warts" (precancerous lesions enhanced by exposure to UV light), erythema, dermal burns, dermal photosensitivity, acneiform lesions, dermal irritation, mild hepatoxicity, and haematuria. Also, several PAH compounds are immunotoxic, and some suppress selective components of the immune system.

Box 1 Summary toxicological information

ies, and Aquaculture Science (CEFAS) began to sample mussels, crabs, and lobsters from the area. Advice was obtained from the Ministry of Agriculture Fisheries and Food (MAFF) to establish safe levels of consumption of PAHs in shellfish. Meetings were held with the health authorities, local authorities, Environment Agency, CEFAS, and CIRS to decide on any appropriate restrictions on shellfish consumption. Further sampling and analysis was then 
Table 2 Initial Environment Agency results: August 1997

\begin{tabular}{|c|c|c|c|c|}
\hline \multirow[b]{2}{*}{ Media/chemical } & \multirow[b]{2}{*}{ Units } & \multicolumn{2}{|l|}{ Standards } & \multirow[b]{2}{*}{$\begin{array}{l}\text { Highest recorded } \\
\text { sampling result }\end{array}$} \\
\hline & & $\begin{array}{l}\text { UK soil }{ }^{6} \text { and } \\
\text { drinking water }\end{array}$ & $\begin{array}{l}\text { Dutch soil }{ }^{7} \text { and } \\
\text { WHO drinking } \\
\text { water }^{8}\end{array}$ & \\
\hline \multicolumn{5}{|l|}{ Sediment: } \\
\hline Total PAHs & $\mathrm{mg} / \mathrm{kg}$ & $50^{*}$ & $40 \dagger$ & $75500 \ddagger$ \\
\hline \multicolumn{5}{|l|}{ Seawater: } \\
\hline Total PAHs & $\mathrm{ng} / 1$ & $200 \Omega$ & - & $728.4 \pi$ \\
\hline Benzo(a)pyrene & $\mathrm{ng} / 1$ & 10 & 700 & 82.8 \\
\hline Phenol & $\mathrm{ng} / 1$ & 500 & - & 277 \\
\hline Ammoniacal nitrogen & $\mathrm{mg} / 1$ & $0.5^{\star \star}$ & $1.5^{\star \star}+\dagger$ & 0.04 \\
\hline Total cyanide & $\mathrm{mg} / 1$ & - & - & 0.0139 \\
\hline \multicolumn{5}{|l|}{ Seepage water: } \\
\hline Total PAHs & $\mathrm{ng} / 1$ & $200 \Omega$ & - & 322.69 \\
\hline Benzo(a)pyrene & $\mathrm{ng} / 1$ & 10 & 700 & 57 \\
\hline Phenol & $\mathrm{ng} / 1$ & 500 & - & 882 \\
\hline Ammoniacal nitrogen & $\mathrm{mg} / 1$ & $0.5^{\star \star}$ & $1.5^{\star \star}+\dagger$ & 1.92 \\
\hline Total cyanide & $\mathrm{mg} / 1$ & - & - & 1060 \\
\hline Free cyanide & $\mathrm{mg} / 1$ & 0.05 & 0.07 & 0.0534 \\
\hline
\end{tabular}

Numbers in bold indicate recorded concentrations that are above the specified standards. -No standard available.

^For domestic gardens, allotments, play areas.

†Total PAHs=sum of anthracene, benzo(a)anthracene, benzo(a)fluoranthene, benzo(a)pyrene, chrysene, phenanthrene, fluoranthene, indeno(1,2,3-cd)pyrene, naphthalene, and benzo(ghi) perylene.

$\ddagger$ Total PAHs=sum of benzo(a)pyrene, benzo(b)fluoranthene, benzo(ghi)perylene, benzo(k) fluoranthene, fluoranthene, indeno(1,2,3-cd)pyrene, acenaphthene, benzo(a)anthracene, chrysene, anthracene, pyrene, and dibenzo(ah)anthracene.

\Total PAHs=sum of fluoranthene, benzo(b)fluoranthene, benzo(k)fluoranthene, benzo(a)pyrene, benzo(ghi)perylene, and indeno(1,2,3-cd)pyrene.

qTotal PAHs=sum of benzo(a)pyrene, benzo(b)fluoranthene, benzo(ghi)perylene, benzo(k) fluoranthene, fluoranthene, and indeno(1,2,3-cd)pyrene.

$\star \star$ Measured as ammonia or ammonium ions.

††Set for customer complaints for odour and taste. No health based guideline value.

Table 3 Combined Environment Agency and Water Research Centre water results: February and March 1998

\begin{tabular}{|c|c|c|c|}
\hline \multirow[b]{2}{*}{ Substance } & \multirow{2}{*}{$\begin{array}{l}\text { Highest recorded } \\
\text { concentration in } \\
\text { water }\end{array}$} & \multicolumn{2}{|l|}{ Standards } \\
\hline & & $\begin{array}{l}\text { UK drinking water } \\
\text { standard }^{7}\end{array}$ & $\begin{array}{l}\text { WHO drinking } \\
\text { water guidelines }{ }^{8}\end{array}$ \\
\hline Free cyanide $(\mu \mathrm{g} / \mathrm{l})$ & 9.9 & 50 & 70 \\
\hline Ammonia $(\mu \mathrm{g} \mathrm{N} / \mathrm{l})$ & 2290 & $500 \mu \mathrm{g} \mathrm{NH}_{4} / 1$ & $1500 \mu \mathrm{g} \mathrm{NH}_{4} / 1^{\star}$ \\
\hline Benzo(a)pyrene (ng/l) & 18.0 & 10 & 700 \\
\hline Total PAHs (ng/l) $\dagger$ & $<98.3$ & 200 & - \\
\hline Phenol ( $\mu \mathrm{g} / \mathrm{l})$ (seawater sample) & 0.139 & $0.5 \mu \mathrm{g} \mathrm{C}_{6} \mathrm{H}_{5} \mathrm{OH} / 1$ & - \\
\hline Mercury $(\mu \mathrm{g} / 1)$ (seawater sample) & 0.31 & 1 & 1 \\
\hline Lead $(\mu \mathrm{g} / \mathrm{l})$ & 4.3 & 50 & 10 \\
\hline Arsenic $(\mu \mathrm{g} / \mathrm{l})$ & 4.01 & 50 & 10 \\
\hline Chromium $(\mu \mathrm{g} / \mathrm{l})$ & 29.4 & 50 & 50 \\
\hline Manganese $(\mu \mathrm{g} / \mathrm{l})$ & 180 & 50 & $100 \ddagger$ \\
\hline Iron $(\mu \mathrm{g} / \mathrm{l})$ & 1400 & 200 & $300 \$$ \\
\hline
\end{tabular}

The highest recorded results are from seepage samples, except where specified as sea water.

Numbers in bold indicate recorded concentrations that are above the specified standards.

-No standard available.

${ }^{\star}$ Set for customer complaints for odour and taste. No health based guideline value.

†Total PAHs=sum of fluoranthene, benzo(b)fluoranthene, benzo(k)fluoranthene, benzo(a)pyrene, benzo(ghi)perylene, and indeno (1,2,3-cd)pyrene.

$\ddagger$ Set for customer complaints for staining of laundry and sanitaryware. Health based provisonal guideline value is $500 \mu \mathrm{g} / \mathrm{l}$.

§Set for customer complaints for staining of laundry and sanitaryware. No health based guideline value.

Table 4 Combined Environment Agency and Water Research Centre sediment results: February and March 1998

\begin{tabular}{|c|c|c|c|}
\hline \multirow[b]{2}{*}{ Substance } & \multirow{2}{*}{$\begin{array}{l}\text { Highest recorded } \\
\text { concentrations in sediments }\end{array}$} & \multicolumn{2}{|l|}{ Standards } \\
\hline & & Soil: Dutch ${ }^{7}$ & Soil: $U K^{6}$ \\
\hline Total cyanide $(\mathrm{mg} / \mathrm{kg})$ & 1.0 & $50^{\star}$ & $250 t$ \\
\hline Benzo(a)pyrene (mg/kg) & 0.0011 & - & - \\
\hline Arsenic (mg/kg) & 5.1 & 55 & $10 \ddagger, 40 \S$ \\
\hline Iron $(\mathrm{mg} / \mathrm{kg})$ & 7652 & - & - \\
\hline
\end{tabular}

-No standard available.

${ }^{\star}$ Complex cyanide $(\mathrm{pH}>5)$.

†Complex cyanide, for domestic gardens, allotments.

$\ddagger$ For domestic gardens, allotments.

§For parks, playing fields, open space. carried out to establish PAH concentrations in mussels over a wider area.

STAGE FOUR

After several months of routine monitoring of the beach sediments, seepage water, and seawater, a review was conducted to assess any significant changes in the concentrations of contaminants on the beach. The sampling strategy was also reassessed at this stage in the light of further results, as it was necessary to establish whether to continue the monitoring programme in its current form or to increase or decrease the number of chemicals being analysed and the frequency of sampling.

\section{Results}

A series of analytical results from the environmental sampling was obtained at the various stages of the investigation, and compared with contaminated land and drinking water standards. Initial results, before the involvement of the health authorities, identified high concentrations of PAHs in sediment and raised concentrations of total PAHs and benzo(a)pyrene in seawater and seepage water. Seepage water was also found to have increased concentrations of phenol, ammoniacal nitrogen, and cyanide (table 2).

Results from further sampling of sediment, seawater, and seepage water carried out in stage one of the investigation by both the Environment Agency and Water Research Centre laboratories were comparable. Increased concentrations of ammonia and benzo(a)pyrene as well as manganese and iron were found in seepage water; however, cyanide and phenol were below drinking water standards (table 3 ).

Results from sediment analysis found no concentrations above contaminated land standards (table 4).

Results from the long term routine monitoring programme carried out by the local authorities and the Environment Agency found increased concentrations of ammonia in seawater, phenol, cyanide, and arsenic in seepage water, and total PAHs in both seawater and seepage water (table 5).

The further chemical analyses carried out on shellfish measured concentrations of total PAHs to be between 4.9 and $6450 \mu \mathrm{g} / \mathrm{kg}$ wet weight, with the lower values occurring in the crustacea and the higher concentrations in the mussels. Concentrations of benzo(a)pyrene (a $\mathrm{PAH}$ ) ranged from 0 to $269 \mu \mathrm{g} / \mathrm{kg}$ wet weight. ${ }^{13}$

PUBLIC HEALTH MANAGEMENT ACTIONS

At the various stages of the investigation the health authority, in consultation with the other agencies, needed to make decisions about management actions that should be taken to protect public health. There were three main time points at which management actions had to be decided upon: (a) after the initial sampling and analysis programme; $(b)$ after the results from the shellfish investigation; and (c) on the results from the long term monitoring programme and its further continuance. 
Table 5 Results from Local Authority and Environment Agency long term monitoring: fuly 1998 to February 2000

\begin{tabular}{|c|c|c|c|c|}
\hline \multirow[b]{2}{*}{ Media/chemical } & \multirow[b]{2}{*}{ Units } & \multicolumn{2}{|l|}{ Standards } & \multirow[b]{2}{*}{$\begin{array}{l}\text { Highest recorded } \\
\text { sampling result }\end{array}$} \\
\hline & & $\begin{array}{l}\text { UK soil }{ }^{6} \text { and } \\
\text { drinking water }\end{array}$ & $\begin{array}{l}\text { Dutch soil }{ }^{7} \text { and } \\
\text { WHO drinking } \\
\text { water }^{8}\end{array}$ & \\
\hline \multicolumn{5}{|l|}{ Sediment: } \\
\hline Total PAHs & $\mathrm{mg} / \mathrm{kg}$ & $50^{\star}$ & $40 \dagger$ & 1.6 \\
\hline Phenol & $\mathrm{mg} / \mathrm{kg}$ & $5 \pm$ & 40 & 0.42 \\
\hline Ammonia & $\mathrm{mg} / \mathrm{kg}$ & - & - & 5.83 \\
\hline Total cyanide & $\mathrm{mg} / \mathrm{kg}$ & $250 \$$ & 50 ฯ & 2.8 \\
\hline Arsenic & & $10^{\star \star}, 40+t$ & 55 & 16.7 \\
\hline \multicolumn{5}{|l|}{ Seawater: } \\
\hline Total PAHs & $\mathrm{mg} / 1$ & $0.0002 \pm \neq$ & - & 0.002806 \\
\hline Phenol & $\mathrm{mg} / 1$ & 0.0005 & - & 0.000392 \\
\hline Ammonia & $\mathrm{mg} / 1$ & 0.5 & 1.500 & 0.536 \\
\hline Total cyanide & $\mathrm{mg} / 1$ & 0.05 (free) & 0.07 (free) & 0.046 \\
\hline Arsenic & $\mathrm{mg} / \mathrm{l}$ & 0.05 & 0.01 & - \\
\hline \multicolumn{5}{|l|}{ Seepage water: } \\
\hline Total PAHs & $\mathrm{mg} / 1$ & $0.0002 \ddagger \ddagger$ & - & 0.014 \\
\hline Phenol & $\mathrm{mg} / 1$ & 0.0005 & - & 0.015 \\
\hline Ammonia & $\mathrm{mg} / 1$ & 0.5 & $1.58 S$ & 0.15 \\
\hline Total cyanide & $\mathrm{mg} / \mathrm{l}$ & 0.05 (free) & 0.07 (free) & 0.7 \\
\hline Arsenic & $\mathrm{mg} / 1$ & 0.05 & 0.01 & 0.15 \\
\hline
\end{tabular}

Numbers in bold indicate recorded concentrations that are above the specified standards. ^For domestic gardens, allotments, play areas.

†Total PAHs=sum of anthracene, benzo(a)anthracene, benzo(a)fluoranthene, benzo(a)pyrene, chrysene, phenanthrene, fluoranthene, indeno(1,2,3-cd)pyrene, naphthalene, and benzo(ghi)perylene.

†For domestic gardens, allotments.

¿Complex cyanide, for domestic gardens, allotments.

$\uparrow$ Complex cyanide $(\mathrm{pH}>5)$.

$\star \star$ For domestic gardens, allotments.

††For parks, playing fields, open space.

†Sum of fluoranthene, benzo(b)fluoranthene, benzo(k)fluoranthene, benzo(a)pyrene, benzo(ghi) perylene, and indeno(1,2,3-cd)pyrene.

$\int \mathcal{S}$ et for customer complaints for odour and taste. No health based guideline value.

\section{Initial assessment}

The initial assessment was based on the earlier results from the Environment Agency investigations conducted in April and August 1997 and the detailed follow up investigation by the local authorities and the Environment Agency in February to March 1998. Data from table 2 in the results section show individual high concentrations of PAHs in one sediment sample and cyanide in one water sample. The more extensive repeat sampling reported on in tables 3 and 4 does not confirm this level of contamination. The results from the second study show that even the highest concentrations found are largely below contaminated land and drinking water standards. The exceptions are:

- Ammonia - the highest concentration in water exceeded both the United Kingdom and WHO standards, but these concentrations have been set largely to avoid complaints of odour and taste

- Benzo(a)pyrene-the maximum concentration recorded in water exceeded the United Kingdom standard, but was well below the WHO guideline value

- Manganese and iron-increased concentrations were found in the water samples, but both standards have been set for aesthetic, rather than health reasons.

The conclusion drawn from these results was that the beach was indeed contaminated. However, at the concentrations found, it was decided that the contamination did not pose a risk to the health of beach users and no action was taken to close the beach. The high concentrations of PAHs and cyanide found in the initial analyses were not repeated. Clarification of the reasons for the original high concentrations was still required, although it was suspected that the very high concentration of PAHs found in the sediment resulted from a sampling or analytical error. The initial high cyanide concentration referred to total cyanide, rather than free cyanide.

Although closure of the beach was not necessary, a long term routine monitoring programme was established to ensure that contaminant concentrations remained low, and to provide early warnings of any potentially hazardous changes. Also, it was suggested that effects on the food chain should be investigated.

The most likely source of contamination, as indicated from the analysis of contaminants, was the former gasworks. An alternative hypothesis was that the pollution may have been caused by a marine pollution incident. However, oil typing carried out as part of the Environment Agency investigation found that the oil had the characteristics of weathered crude, which indicated heavy oil or tar as the source, rather than transport oils. Another possibility was that sediment material added to the beach may have been contaminated.

\section{Food chain investigation}

The earlier investigation by the Environment Agency in August 1997 included a biological survey which concluded that the pollution of the beach had impacted on the macroinvertebrate fauna within the beach, hence the problem with fishing bait. Subsequent food chain investigations started in March 1999 and provided no evidence of notable PAH contamination of crustacea. Likewise fish would not be expected to show increased concentrations of PAHs both because they are more mobile and because they are able to metabolise PAHs more rapidly ( $\mathrm{R}$ Law, CEFAS personel communication). However, due to the nature of the behaviour and biological mechanisms of mussels, it was found that high concentrations of PAHs were being bioaccumulated in the mussel flesh. The concentrations were such that it was decided that warning signs should be erected on the beach to ensure that mussels were not collected for human consumption. However, the location, extent, and quality of the mussels in the vicinity of the beach meant that collection of many mussels was unlikely.

\section{Long term monitoring programme}

The implementation of a long term monitoring programme clearly had resource implications, but enabled the monitoring and assessment of the activity of any contaminants, and also allowed for the build up of a long term picture of what was happening both on the original gasworks site, and the beach and sea beyond. The Environment Agency took responsibility for monitoring the seawater on a routine basis and also periodically sampled seepage water and sediment. The local authorities took responsibility for routine sampling of the beach sediment and seepage water. Monitoring results were shared between all the parties involved. The routine long term monitoring showed little change in the environmental concentrations of the chemicals of concern on the 


\section{Collaboration and coordination}

Vital for effective incident management and efficient exchange of information.

Requires recognition and understanding of the roles and statutory powers of those involved in incident management.

The need to alert the local health authority as soon as a possible threat to public health is established.

\section{Assessment of contamination}

Importance of early sampling to assess the level of exposure before conducting a risk assessment.

Need for a comprehensive sampling and analysis programme to obtain a representative picture of the types and concentrations of contaminants.

Identification of the peaks and troughs in chemical concentrations.

Need for repeat sampling and if possible collection and analysis of duplicate samples.

Identification of the source of the contamination, and the pathways providing any routes for human exposure.

\section{Dissemination of information}

There is considerable disparity between the number of incidents that are occurring and those that are published.

Lessons learnt from this case study and their wider application highlights the importance of publication and dissemination.

Both documentation and publication of these incidents are necessary to make use of the valuable information accumulated in managing incidents.

Box 2 Summary of lessons learnt

beach, therefore the next stage was to consider the possibility of reducing the number of variables and frequency of sampling; however, some form of environmental monitoring would need to continue.

\section{Discussion}

An important aspect of the investigation into a chemical incident is analysis of the investigation process and identification of positive and negative aspects of the management of the incident. Several lessons can be learnt from this investigation, which can be applied to incident management more generally, these are summarised in box 2 .

COLLABORATION AND COORDINATION

From the outset of this incident it was clear that collaboration and coordination of all the parties was essential, and this had to include recognition and understanding of the roles and statutory powers of each, and an efficient exchange of information. In this case all the parties involved worked well together. However, a difficult area was the allocation of responsibility for sampling, partly because of the considerable costs involved. Ideally, these issues should be resolved at the start of the incident, with reference to the statutory obligations of the organisations involved. Also, the local health authority needs to be alerted as soon as a possible threat to public health is established. In this incident, the local authority identified the importance in terms of public health on receiving the Environment Agency report, and the health authority was immediately informed. In some situations it can be difficult to know whether or not there are likely to be health implications, and in this case if there had been ongoing health effects from the beach contamination, the delay from the initial report in April 1997 would have been substantial.

\section{ASSESSMENT OF CONTAMINATION}

It is important that sampling is undertaken early, so as to assess the level of exposure, then a risk assessment can be conducted. To obtain a representative picture of the types and concentrations of contaminants a comprehensive sampling and analysis programme should be instigated. The peaks and troughs in concentrations should be identified. Repeat samples should be taken, and ideally duplicate samples should be collected and analysed. Samples should be retained for any necessary repeat analysis. Another high priority is to identify the source of the contamination, and the pathways providing any routes for human exposure, including secondary contamination, which may occur from activities such as fishing, food crops, and food preparation. With the levels and route of exposure identified, the actual risk to health and the environment can be assessed.

\section{DISSEMINATION OF INFORMATION}

A literature review over the years 1994-7 for chemical incidents in the United Kingdom affecting water, conducted as part of an ongoing research project, identified only eight incident reports published in peer reviewed journals. ${ }^{13} \mathrm{By}$ contrast, data compiled by CIRS, from 1997 alone, contained 31 reports of chemical incidents that actually, or potentially, affected water and resulted in a threat to human health. This large difference indicates the size of the disparity between the number of incidents that are occurring and those that are published.

The lessons learnt from this case study and their wider application highlight the importance of publication and dissemination. The need for dissemination is made more apparent when the number of gasworks sites across the United Kingdom is taken into account, as stated previously, it is estimated that there are in the region of 1000 former gasworks sites in the United Kingdom. ${ }^{3}$

Both documentation and publication of these incidents is necessary to make use of the valuable information accumulated in managing incidents and to inform those involved in the management of chemical incidents on current practice. This information would be of particular benefit to public health professionals, who may only be called on to respond to incidents on an infrequent basis. 


\section{Conclusions}

The investigation into the possible impact on public health from a beach contaminated with chemicals migrating from an adjacent former gasworks site started with a comprehensive environmental sampling and analysis exercise. It was concluded that although contaminated to a limited extent, the beach did not pose a health risk to users of the beach. The decision on beach closure was important because of the impact on users and tourists. Chemical analysis by two independent laboratories was particularly beneficial in such an incident, where very high early results were not subsequently confirmed. A routine long term monitoring programme was established to identify any changes in chemical concentrations over time. An investigation into the impact of $\mathrm{PAH}$ contamination of the seawater on the food chain, focusing on shellfish in particular, was also conducted. This investigation resulted in warning signs being put up on the affected beach to prevent human consumption of mussels contaminated with PAHs.

Several lessons can be learnt from this investigation, which can be applied to incident management more generally: the importance of collaboration and coordination; the need to alert the local health authority in the event of an incident as soon as a possible threat to public health is indicated; and the importance of carrying out appropriate sampling and analysis as soon as possible, to assess the risk to health and the environment.
We thank Dr Howard Eastcott for his assistance in the management of the incident. The support of the local authorities, the Environment Agency, and CEFAS is gratefully acknowledged, in particular from Paul Slaughter, Trevor Hodgson, Ian Grey, George Smith, and Robin Law. The assistance of the Environment Agency and Water Research Centre in providing the analytical results is also very much appreciated. Finally, thanks are also due to the local port authority for allowing access to the beach and past reports on the site. Financial support to FJLG from EPSRC as part of the engineering doctorate programme in environmental technology at the University of Surrey is gratefully acknowledged.

1 NHS Management Executive. Public health: responsibilities of he NHS and the roles of others. Leeds: NHS, 1993. HSG(93)56.

2 NHS Executive. Chemical incidents. In: NHS Executive. Planning for Major incidents - the NHS guidance. London: NHS Executive, 1998:97-118.

3 19th Royal Commission report on environmental pollution. London: HMSO, February 1996. (Cm 3165.)

4 Department of Environment. Gas works, coke works, and other coal carbonisation plants. London: Department of Environment, 1995. (Industry profile sponsored by the contaminated land and liabilities division).

5 Grey I. Potential pollution arising from former gas works, Shoreham Harbour, results of environmental monitoring. Sussex, UK: Environment Agency, January 1998 .

6 Interdepartmental Committee on the Redevelopment of Contaminated Land. Guidance on the assessment and redevelopment of contaminated land, 2 nd ed. London: Department opment of contaminated land,

7 Croner. Substances hazardous to the environment. Kingston, Surrey: Croner, June 1996.

8 World Health Organisation. Guidelines for drinking water quality, 2nd edition. Geneva: WHO, 1996.

9 Farrow C, Wheeler H, Bates N, et al, eds. The chemical incident management handbook. London: The Stationary Office, 2000 .

10 Hathaway GJ, Proctor NH, Hughes JP. Proctor and Hughes' chemical hazards of the workplace, 4th ed. New York: Van Nostrand Reinhold, 1996.

11 Grant MW, Schuman JS. Toxicology of the eye, 4th ed. Springfield, CA: Charles C Thomas, 1993.

12 TOMES Plus System. Vol 33. Englewood, Colorado: Micromedex, 1997.

13 Oliver F, Holmes EM. Identifying chemical water incidents in the published literature. Chemical Incident Report 1998;8 $2-9$.

\section{Correspondence and editorials}

Occupational and Environmental Medicine welcomes correspondence relating to any of the material appearing in the journal. Results from preliminary or small scale studies may also be published in the correspondence column if this seems appropriate. Letters should be not more than 500 words in length and contain a minimum of references. Tables and figures should be kept to an absolute minimum. Letters are accepted on the understanding that they be subject to editorial revision and shortening.

The journal also publishes editorials which are normally specially commissioned. The Editor welcomes suggestions regarding suitable topics; those wishing to submit an editorial, however, should do so only after discussion with the Editor. 